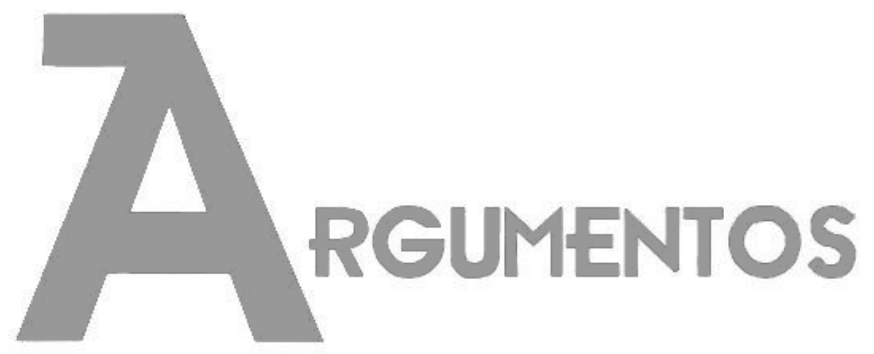

Vol. 16, n. 2, jul./dez. 2019 ISSN: 2527-2551 (online)

http://www.periodicos.unimontes.br/argumentos

\title{
Orçamento público para financiamento da assistência estudantil no ensino superior sob a perspectiva do direito humano fundamental à educação
}

\author{
Paulo Fernando de Melo Martins ${ }^{1}$ \\ Carlos Alberto Moreira de Araújo Junior ${ }^{2}$ \\ Jacqueline Araújo Rodrigues ${ }^{3}$
}

Recebido em: 09/01/2019

Aprovado em: 20/05/2019

Resumo: Este estudo delimitou como proposta de reflexão o orçamento público destinado ao financiamento da assistência estudantil como direito humano fundamental à educação. Assim, em referência ao princípio da vedação do retrocesso social, o problema de pesquisa residiuem compreender como se comportaram as dotações orçamentárias para o Programa Nacional de Assistência Estudantil (PNAES) e quais ações de assistência foram atendidas no contexto de uma Instituição Federal de Ensino Superior (IFES), no período de 2010 a 2018. A proposta metodológica norteia-se num estudo descritivo, com uso das pesquisas qualiquantitativas. A estratégia deste estudo para coleta e análise dos dados foi conduzida por meio das pesquisas documental e bibliográfica. O orçamento deste Programa tem sofrido retrações, justifica-se, pois, a divulgação das informações sobre o volume de recursos e sua execução, principal mente pelo risco de retrocesso social diante do projeto de reforma das atividades estatais arquitetado por grupos políticos de orientação neoliberal.

\footnotetext{
1 Professor Adjunto da Universidade Federal do Tocantins (UFT), Brasil. Doutor em Educação. Leciona no curso de Pedagogia e no Mestrado Profissional em Prestação Jurisdicional e Direitos Humanos da Universidade Federal do Tocantins (UFT), Brasil. Coordena o Núcleo Interdisciplinar de Educação em Direitos Humanos (NIEDIH/UFT). E-mail: paulofernando@mail.uft.edu.br. ORCID: https://orcid.org/00000003-3551-8363.

2 Mestrando do Programa de Mestrado Profissional em Prestação Jurisdicional e Direitos Humanos da Universidade Federal do Tocantins (UFT), Brasil. Bacharel em Administração pelo Centro Universitário Luterano de Palmas - TO (CEULP/ULBRA), Brasil. 2004. Servidor da Universidade Federal do Tocantins no cargo de Administrador.E-mail:adm.junior@uft.edu.br. ORCID: https://orcid.org/0000-0003-2230-4155.

${ }^{3}$ Mestranda do Programa de Pós-graduação Stricto Sensu em Prestação Juris dicional e Direitos Humanos da UFT. Graduada em Direito pela Universidade Federal do Tocantins (UFT), Brasil, 2009. Servidora da Universidade Federal do Tocantins, Brasil. E-mail: jackrodrigues@gmail.com. ORCID: https://orcid.org/0000-0002-2372-4285.
} 
Artigo | Orçamento público para financiamento da assistência estudantil no enșino superior sob a perspectiva do direito humano fundamental à educação (MARTINS, Paulo Fernando de Melo; ARAÚJO JUNIOR, Carlos Alberto Moreira de; RODRIGUES, Jacqueline Araújo.

Palavras-chave: Orçamento Público. Assistência Estudantil. Vedação do Retrocesso Social. Direitos Humanos.

\title{
Presupuesto público para financiamiento de la asistencia estudiantil en el enseño superior bajo la perspectiva del derecho humano fundamental a la educación
}

Resumen: Este estudio delimitó como una propuesta de reflexión al presupuesto público destinado al financiamiento de la asistencia estudiantil como derecho humano fundamental a la educación. Así, en referencia del principio del vedación del retroceso social, el problema de investigación residió en comprender cómo se comportaron los créditos presupuestarios para el Programa Nacional de Asistencia Estudiantil (PNAES) y qué acciones de asistencia fueron atendidas en el contexto de una Institución Federal del Enseño Superior (IFES), en el período de 2010 a 2018. La propuesta metodológica se orienta en un estudio descriptivo, con el uso de las investigaciones cualitativas. La estrategia de este estudio para la recolección y análisis de los datos fue conducida por medio de las investigaciones, documentos y bibliográfica. El presupuesto de este Programa ha sufrido retrasos, se justifica, pues, la divulgación de las informaciones sobre el volumen de recursos y su ejecución, principalmente por el riesgo de retroceso social ante el proyecto de reforma de las actividades estatales, diseñado por grupos políticos de orientación neoliberal.

Palabras-clave: Presupuesto Público. Asistencia Estudiantil. Vedación del Retroceso Social. Derechos Humanos.

\section{Public budget for the financing of student assistance in higher education under the perspective of fundamental human rights to education}

\begin{abstract}
This study determined as a reflection proposal the public budget destined to the financing of student assistance as a fundamental human right to education. Thus, in reference to the principle of the prohibition of social regression, the research problem resided in understanding how to behave the budget allocations for the National Program of Student Assistance (PNAES) and what assistance actions were taken in the context of a Federal Education Institution (IFES) in the period from 2010 to 2018. The methodological proposal is based on a descriptive study, using quali-quantitative research. The strategy of this study for data collection and analysis was conducted through documental and bibliographic research. The budget of this program has suffered retraction, it is justified, therefore, the dissemination of information about the volume of resources and its execution, mainly due to the risk of social regression in the face of the project of reform of the state activities designed by political groups with neoliberal orientation.
\end{abstract}

Keywords: Public Budget. Student Assistance. Prohibition of a Social Regression. Human Rights.

\section{Introdução}

Este trabalho tem como foco de pesquisa o financiamento da assistência estudantil a partir da aprovação do Programa Nacional de Assistência Estudantil (PNAES), importante política pública que busca ampliar as condições de permanência de estudantes na educação superior e a igualdade das condições de seu acesso, salvaguardando, dessa forma, o direito humano fundamental à educação. 
Artigo | Orçamento público para financiamento da assistência estudantil no enșino superior sob a perspectiva do direito humano fundamental à educação (MARTINS, Paulo Fernando de Melo; ARAÚJO JUNIOR, Carlos Alberto Moreira de; RODRIGUES, Jacqueline Araújo.

Vale lembrar que a partir dos anos 2000 houve intensa articulação para inclusão de políticas públicas de acesso ao ensino superior, a exemplo do Programa Nacional de Assistência Estudantil, que oferece assistência à moradia estudantil, alimentação, transporte, saúde, inclusão digital, cultura, esporte, creche e apoio pedagógico, ações estas executadas pelas Instituições Federais de Ensino Superior que demandam recursos públicos para sua realização.

Ocorre que vigoram atualmente no Brasil as soluções políticas relacionadas ao projeto de reforma das atividades estatais arquitetado por grupos políticos sob orientação neoliberal, com fundamento na lógica de minimização do papel do Estado e ampliação do espaço privado; esta ideologia não prioriza as políticas públicas sociais, em particular o ensino superior público.

Nesse contexto, torna-se bastante visível a atual crise de financiamento à educação superior com a universidade pública inserida no meio das disputas políticas e ideológicas sobre a destinação de recursos no âmbito do orçamento público, pois é no orçamento que os governos definem as prioridades do plano de governo que podem impactar e/ou obstar a realização de políticas públicas em temas afetos aos direitos humanos.

Por isso, tendo em vista a importância do Programa para a democratização do acessoao ensino superior, a política de destinação de recursos orçamentários a ele deve ser executada de forma articulada ao princípio da vedação do retrocesso social pela importante limitação à reversão das conquistas sociais.

Conforme ensinam Taveira \& Marçal (2013, p.163), por este princípio não se permitem, por exemplo, "condutas que impliquem retrocesso das conquistas alcançadas". Desse modo, com o objetivo de refletir sobre a execução do orçamento destinado ao Programa, na perspectiva do princípio da vedação do retrocesso social e a realização dos direitos humanos, o problema de pesquisa residiu em compreender como se comportaram as dotações orçamentárias para o Programa e quais ações de assistência foram atendidas no contexto de uma Instituição Federal de EnsinoSuperior (IFES), no período de 2010 a 2018.

Este estudo revela, por fim, que o orçamento das Leis Orçamentárias Anuais (LOA), no Programa, tem sofrido retração, e, em vista da necessidade de continuação e ampliação do Programa Nacional de Assistência Estudantil, mediante a atual orientação 
Artigo | Orçamento público para financiamento da assistência estudantil no enșino superior sob a perspectiva do direito humano fundamental à educação (MARTINS, Paulo Fernando de Melo; ARAÚJO JUNIOR, Carlos Alberto Moreira de; RODRIGUES, Jacqueline Araújo.

neoliberal de reforma das atividades estatais, o acesso às informações sobre a destinação e a execução do orçamento público fortalece o monitoramento e a participação social, com foco na efetivação das políticas públicas, a fim de não permitir o retrocesso em temas afetos aos direitos humanos, em especial, o ensino superior.

\section{Procedimentos metodológicos}

Este estudo permitiu uma reflexão a respeito do orçamento público da Lei Orçamentária Anual (LOA), destinado ao Programa Nacional de Assistência Estudantil no âmbito da Universidade Federal do Tocantins (UFT), e abriu espaço para exploração e discussão sobre o tema: Orçamento Público e Financiamento da Assistência Estudantil na Perspectiva de Direito Humano Fundamental. Verificaram-se, nesta pesquisa, a evolução do orçamento e a execução orçamentária, no período de 2010, época de edição do Decreto regulamentador da assistência estudantil, até 2018, último orçamento disponível no momento da pesquisa. Sãos os recursos aprovados pelas Leis Orçamentárias Anuais (LOAs) e os créditos aprovados ou autorizados em contraste com os valores do orçamento comprometidos, dito como empenhados.

Para cumprimento do objetivo proposto, a proposta metodológica norteia-se num estudo descritivo, com uso das pesquisas qualiquantitativas. A estratégia deste estudo para coleta e análise dos dados foi conduzida por meio das pesquisas documental e bibliográfica.

A pesquisa documental contou com as informações da base de dados do Tesouro Gerencial, sistema para consulta de informações do Sistema Integrado de Administração Financeira (SIAFI), documento institucional, relatório da Pró-Reitoria de Assuntos Estudantis (PROEST) e Orçamento Anual (LOA).

Para a pesquisa bibliográfica, foram selecionados artigos científicos, livros, legislação, jurisprudência e dissertação, material em convergência com o objetivo da pesquisa. Não houve estipulação de data referente à publicação das obras. Foram escolhidas as seguintes palavras-chave: orçamento público, assistência estudantil, vedação do retrocesso e direitos humanos. 
Artigo | Orçamento público para financiamento da assistência estudantil no enșino superior sob a perspectiva do direito humano fundamental à educação (MARTINS, Paulo Fernando de Melo; ARAÚJO JUNIOR, Carlos Alberto Moreira de; RODRIGUES, Jacqueline Araújo.

\section{Direitos humanos e a proibição do retrocesso social}

A conquista dos direitos humanos pode ser concebida como fruto de reivindicação e movimentação social ao longo dos tempos. Como sintetiza a professora Piovesan (2012, p. 175), "No dizer de Hannah Arendt, os direitos humanos não são um dado, mas um construído, uma invenção humana, em constante processo de construção e reconstrução". Na concepção de Hunt (2009, p. 19), "são direitos que requerem uma participação ativa daqueles que os detêm", devem ser naturais, ou seja, peculiares aos seres humanos, iguais para todos os homens, e universais.

Importante rememorar, desse modo, que o cenário de fome, epidemias e enorme concentração de terras e poder nas mãos de poucos impulsionou o clamor social na idade média pela instituição dos direitos humanos contra injustiças e desigualdades. Já na modernidade, alguns eventos são considerados basilares para a conquista dos direitos humanos, com especial destaque à Independência dos Estados Unidos e à Revolução Francesa.

No caso americano, houve levante popular pela autonomia enquanto nação, liberdade e rompimento com o sistema colonial, a Declaração da Independência, de 1776, defendeu a ideia da igualdade entre todos os homens, dotados por Deus de certos direitos inalienáveis que não podiam ser tirados, eram livres para a vida, para a busca da felicidade.

Na França do século XVIII, a sociedade vivenciou a luta pela proclamação de direitos, com base nos valores da liberdade, igualdade e fraternidade, a Declaração dos Direitos do Homem e do Cidadão, de 1789, permitiu uma regulamentação mais cuidadosa dos direitos humanos.

A movimentação social pela organização do Estado e a limitação do poder estatal impulsionaram o surgimento das constituições com previsão escrita dos direitos humanos fundamentais em reação aos Estados absolutistas e para garantia de direitos a uma parcela reduzida da população. A esse respeito, na concepção de Silva (2006), os direitos humanos fundamentais, 
Artigo | Orçamento público para financiamento da assistência estudantil no enșino superior sob a perspectiva do direito humano fundamental à educação (MARTINS, Paulo Fernando de Melo; ARAÚJO JUNIOR, Carlos Alberto Moreira de; RODRIGUES, Jacqueline Araújo.

[...] além de referir-se a princípios que resumem a concepção do mundo e informam a ideologia política de cada ordenamento jurídico, é reservada para designar, no nível do direito positivo, aquelas prerrogativas e instituições que ele concretiza em garantias de uma convivência digna, livre e igual de todas as pessoas (SILVA, 2006, p. 179).

Os direitos fundamentais também são concebidos como interdependentes e determinados por múltiplos fatores históricos, culturais, sociais, políticos e econômicos.

Sem a efetividade dos direitos econômicos, sociais e culturais, os direitos civis e políticos se reduzem a meras categorias formais, enquanto que, sem a realização dos direitos civis e políticos, ou seja, sem a efetividade da liberdade entendida em seu mais amplo sentido, os direitos econômicos sociais e culturais carecem de verdadeira significação. [...] Em suma, todos os direitos humanos constituem um complexo integral, único e indivisível, em que os diferentes direitos estão necessariamente inter-relacionados e são interdependentes entre si. (PIOVESAN, 2012, p. 161).

No século XX, diante de um ambiente de horror provocado em decorrência da $2 \underline{a}$ Guerra Mundial e violações de direitos pelo nazismo, ganha força o fenômeno da internacionalização dos direitos humanos. Nesse contexto, conforme adverte Flávia Piovesan, "Fortalece-se a ideia de que a proteção dos direitos humanos não deve se reduzir ao domínio reservado do Estado, isto é, não deve se restringir à competência nacional exclusiva ou à jurisdição doméstica exclusiva, porque revela tema de legítimo interesse internacional" (PIOVESAN, 2001, p. 2).

Orientada pela proteção internacional dos direitos humanos, a Organização das Nações Unidas (ONU), fundada em 1945, aprovou a Declaração Universal dos Direitos Humanos tendo como referência a universalidade, indivisibilidade e interdependência dos direitos humanos.

Com base na referida declaração, a concepção de direitos humanos se apoia na ideia de igualdade entre todos os seres humanos; não obstante diferentes, são livres e iguais, protegidos pelo sistema global dos direitos fundamentais para a dignidade humana, conquistados entre as diversas gerações.

Segundo expõe Castilho (2011), a dignidade da pessoa humana tem como fundamento os direitos inerentes à personalidade e os direitos estabelecidos para a coletividade, e não se permite nenhum tipo de discriminação (s exo, idade, classe social e outros). Os autores Novelino \& Cunha Júnior (2018, p. 17) asseveram ainda que, "na 
Artigo | Orçamento público para financiamento da assistência estudantil no enșino superior sob a perspectiva do direito humano fundamental à educação (MARTINS, Paulo Fernando de Melo; ARAÚJO JUNIOR, Carlos Alberto Moreira de; RODRIGUES, Jacqueline Araújo.

relação entre o indivíduo e o Estado deve haver sempre uma presunção a favor do ser humano e de sua personalidade".

Bem por isso, no Estado brasileiro a dignidade da pessoa humana é fundamental para a interpretação e aplicação das normas do ordenamento jurídico, é princípio fundamental garantido pela Constituição Federal, de 1988. Nessa perspectiva de promoção e proteção dos direitos humanos, urge ressaltar a procedente advertência de Bobbio (2004, p.16), a de que "o problema fundamental dos direitos do homem, hoje, não é tanto justificá-los, mas o de criar condições para protegê-los. Trata-se de um problema não filosófico, mas político".

Então, tendo em vista a necessidade de efetiva concretização dos direitos humanos é que surge a ideia da proibição do retrocesso social como princípio implícito no ordenamento jurídico pátrio. Esse entendimento ganhou forma no Brasil a partir da Constituição Federal, de 1988, com os direitos e garantias fundamentais, não se excluindo outros praticados em decorrência do regime e princípios adotados no texto constitucional.

Ademais, a partir da edição do Decreto no 591, de 6 de julho de 1922, com o Pacto Internacional sobre Direitos Econômicos, Sociais e Culturais, o Estado vê-se obrigado a promover as condições necessárias à efetivação dos direitos econômicos, sociais e culturais.

Para a professora Piovesan, tais instrumentos normativos estabelecem a obrigação estatal de adoção das medidas necessárias ao pleno alcance, de forma progressiva, dos direitos humanos instituídos, pois "cabe aos Poderes Públicos conferir eficácia máxima e imediata a todo e qualquer preceito definidor de direito e garantia fundamental" (PIOVESAN, 2012, p. 92).

Além disso, a ideia da proibição do retrocesso social aduz que tais medidas devem ser concretizadas e manter o nível já conquistado de realizações; com isso, busca-se evitar o risco de diluição dos direitos sociais mantendo-se, então, a progressiva efetivação dos direitos sociais (NOVELINO \& CUNHA JÚNIOR, 2018).

Convém pontuar a observação de Andrade (2016), para este autor, o princípio da vedação do retrocesso social se impõe pela "fundamentalidade" dos direitos sociais e pelo caráter de progressividade aplicado à realização desses direitos, fato que impõe limites à vontade do legislador com o objetivo de evitar o retrocesso social. 
Artigo | Orçamento público para financiamento da assistência estudantil no enșino superior sob a perspectiva do direito humano fundamental à educação (MARTINS, Paulo Fernando de Melo; ARAÚJO JUNIOR, Carlos Alberto Moreira de; RODRIGUES, Jacqueline Araújo.

Nessa linha de entendimento, Moura \& Ribeiro (2017) defendem a alocação de recursos para concretização dos direitos fundamentais sociais de forma progressiva e crescente à sua efetivação. Como se vê, o princípio da proibição do retrocesso em temas de direitos humanos fundamentais, a exemplo do direito à educação, reconhecido expressamente no artigo 6으 da Constituição Federal, limita a redução ou supressão do nível de realizações já conquistadas pela sociedade.

Sobre esse aspecto, o entendimento do Supremo Tribunal Federal foi o de que o princípio da proibição do retrocesso impede a desconstrução das conquistas já alcançadas pelo cidadão em matéria de direito fundamental social, conforme voto do ministro Celso de Mello, no Agravo Regimental no Recurso Extraordinário com Agravo no 639.337, publicado em 23 de agosto de 2011.

Em cenário de crises econômicas e escassez de recursos, este princípio assume importante papel diante do risco de reversibilidade das conquistas alcançadas pelo cidadão e obriga o Estado a adotar as medidas cabíveis para a aplicação prioritária dos recursos públicos em disponibilidade. Por esse viés de entendimento, conforme entende Barroso (2001), os direitos incorporados ao patrimônio jurídico não podem ser "absolutamente" suprimidos.

É interessante observar, nesse ponto, que o avanço de soluções políticas fundamentadas numa orientação ideológica conservadora e reacionária de enfrentamento das adversidades econômicas, a partir da adoção de uma agenda política neoliberal, em atendimento a setores parlamentares da política nacional associados ao capital financeiro e produtivo, pode proporcionar, dentre outras ações, retrações nas conquistas sociais, como o corrido com a classe trabalhadora.

Por isso, não é admissível inverter a ordem de prioridade constitucional de forma a permitir aprovação de orçamento insuficiente, quando houver disponibilidade, para a implementação dos direitos humanos fundamentais, tendo em vista o risco de retrocesso das conquistas sociais alcançadas, como é o caso da educação superior.

\section{Educação superior como direito humano fundamental}

A educação é um direito humano fruto de conquistas sociais e políticas, assim aduz a Declaração Universal dos Direitos Humanos em seu artigo $26^{\circ}$, "Toda a pessoa 
Artigo | Orçamento público para financiamento da assistência estudantil no enșino superior sob a perspectiva do direito humano fundamental à educação (MARTINS, Paulo Fernando de Melo; ARAÚJO JUNIOR, Carlos Alberto Moreira de; RODRIGUES, Jacqueline Araújo.

tem direito à educação". E, no Brasil, a dignidade da pessoa humana, princípio fundamental para a interpretação e aplicação das normas do ordenamento jurídico, está conectada com a ideia do direito fundamental à educação.

O direito à educação está previsto explicitamente na Constituição Federal, de 1988, e em outros documentos jurídicos relevantes, como pactos internacionais (Pacto Internacional sobre os Direitos Econômicos, Sociais e Culturais), na Lei de Diretrizes e Bases da Educação Nacional (Lei no 9.394, de 1996); Estatuto da Criança e do Adolescente, na Lei no 8.069, de 1990, entre outros. Todo esse arcabouço normativo dá parâmetros aos Poderes Legislativo, Executivo e Judiciário para concretização do direito de acesso à educação de forma igualitária.

De acordo com o Relatório Nacional sobre Direito Humano à Educação, conceber a educação como Direito Humano diz respeito a considerar o ser humano na sua vocação ontológica de querer "ser mais", diferentemente dos outros seres vivos, buscando superar sua condição de existência no mundo. (CANDAU, 2012, p. 715).

Conforme se vislumbra, a legislação brasileira trata a educação como direito universal, haja vista ser um instrumento de formação dos cidadãos na luta por seus direitos. Por esse entendimento, "a educação tem um compromisso com a formação integral do ser humano, fazendo interlocução com todas as dimensões de sua relação com a sociedade" (ALVES, 2002, p. 22).

Portanto, importa destacar que a educação deve ser prestada com a finalidade de atingir os objetivos explícitos constitucionalmente, quais sejam: desenvolvimento da pessoa; preparo para o exercício da cidadania; e qualificação para o trabalho. Em vista disso, a educação deve ser oferecida nos níveis básico e superior, para que realmente haja a efetivação desse direito. É o que corrobora André Lázaro:

As sociedades democráticas, apoiadas na concepção soberana do indivíduo, têm na educação seu mais importante instrumento de afirmação de valores e princípios. A partir das premissas da igualdade perante a lei e da irredutibilidade do indivíduo, as sociedades democráticas apostam no valor equitativo da educação: cada um de acordo com seus méritos terá acesso ao conjunto de direitos e oportunidades reservadas aos seus cidadãos educados. Acessar a educação é premissa para ter acesso à condição de cidadão de pleno direito. (LÁZARO, 2008, p. 26) 
Artigo | Orçamento público para financiamento da assistência estudantil no enșino superior sob a perspectiva do direito humano fundamental à educação (MARTINS, Paulo Fernando de Melo; ARAÚJO JUNIOR, Carlos Alberto Moreira de; RODRIGUES, Jacqueline Araújo.

De acordo com a Lei de Diretrizes e Bases da Educação Nacional, há, no Brasil, dois níveis de educação: a básica que engloba o ensino infantil, fundamental e médio, e a superior. Todos os níveis deveriam ser oferecidos de forma universal e gratuita para quem tivesse interesse; entretanto, ainda faltam políticas públicas que efetivem o acesso igualitário a todos os níveis educacionais à população.

O oferecimento do Ensino Fundamental de forma universal e gratuita está consolidado no Brasil, haja vista a obrigatoriedade de sua prestação pelo Estado, conforme previsão do artigo 4으 da Lei № 9.394, de 1996, ainda que a qualidade seja um grande desafio, e o Ensino Médio permaneça sem o merecido e adequado tratamento. Contudo, historicamente, o Ensino Superior estava adstrito à elite.

Por isso, conforme Chauí (2003, p. 13), a universidade pública deixará de ser um bolsão de exclusões sociais e culturais quando o acesso estiver assegurado pela qualidade e pelo nível dos outros graus do ensino público. O cenário educacional, ao longo de duas décadas, vem sendo alterado aos poucos com a criação de políticas públicas de fomento ao acesso e à permanência no ensino superior.

Convém lembrar que o acesso e a permanência nas universidades são conquistas sociais, resultado de lutas históricas na trajetória da educação (MENEGON, 2018). Por esse motivo, tornar a educação superior universal e facilitar o acesso a todas as pessoas em condições de igualdade é um objetivo a ser perseguido pelo Estado desde sua previsão na Declaração Universal dos Direitos Humanos.

À vista disso, justifica-se o empenho governamental para criação dos instrumentos regulatórios e a proposição de políticas públicas necessárias à sua prática efetiva. E para que as desigualdades sejam minimizadas, torna-se necessário o investimento do Estado para a efetividade da prestação do direito à educação.

Obrigatória, gratuita e universal, a educação só poderia ser ministrada pelo Estado. Impossível deixá-la confiada a particulares, pois estes somente podiam oferecê-la aos que tivessem posses (ou a protegidos), e daí operar antes para perpetuar as desigualdades sociais, que para removê-las. A escola pública, comum a todos, não seria, assim, o instrumento de benevolência de uma classe dominante, tomada de generosidade ou de medo, mas um direito do povo, sobretudo das classes trabalhadoras (TEIXEIRA, 1957, p.80). 
Artigo | Orçamento público para financiamento da assistência estudantil no enșino superior sob a perspectiva do direito humano fundamental à educação (MARTINS, Paulo Fernando de Melo; ARAÚJO JUNIOR, Carlos Alberto Moreira de; RODRIGUES, Jacqueline Araújo.

A partir da década de 1990, com a Constituição Federal, de 1988, cresce a preocupação estatal em instituir políticas públicas de inclusão educacional, com vista ao atendimento dos objetivos constitucionais do direito à educação superior. Ainda que no governo do ex-presidente Fernando Henrique Cardoso não tenha acarretado uma menor procura pelo ensino público, dados oficiais revelam a ocorrência de um crescimento maior no número de matrículas e de instituições no ensino superior no setor privado.

De acordo com Chauí (2003), com a reforma do Estado no final do último governo do ex-presidente Fernando Henrique Cardoso, a educação passou de direito a serviço e pôde ser privada ou privatizada. Isso colaborou com o avanço das correntes políticas defensoras da mercantilização em todos os níveis educacionais.

Para Chauí (2003), esse aspecto se agrava com a inclusão da educação como parte do acordo internacional do comércio, no qual a educação superior passou a ser considerada um serviço. O entendimento de setores das comunidades acadêmicocientíficas confirma o período de desigualdades vivenciado pelo Brasil, o que reflete na precária condição da prestação educacional do nosso Estado:

Contemporaneamente, em função do chamado novo ordenamento econômico e social do capital internacional, o quadro de desigualdades sociais tem-se aprofundado, produzindo uma complexa rede de relações sociais e políticas, expressão do processo de dominação e exploração econômica vivenciados pelos brasileiros. (DIAS, 2007, p. 443)

Nos anos 2000, em especial ao longo do governo do ex-presidente Luís Inácio Lula da Silva, observa-se uma maior articulação das políticas governamentais de acesso ao ensino superior, como, por exemplo, o Programa Universidade para Todos (PROUNI); o Programa de Apoio a Planos de Reestruturação e Expansão das Universidades Federais (REUNI); a Universidade Aberta do Brasil (UAB); as políticas afirmativas no ensino superior (Leis nos 10.639, de 2003, e 12.711, de 2012); e o Programa Nacional de Assistência Estudantil (PNAES), objeto deste estudo.

De acordo com o posicionamento do Supremo Tribunal Federal (STF), conforme o voto do ministro relator Eros Grau, em Agravo Regimental no Recurso Extraordinário no 594.018, publicado em 7 de agosto de 2009, o Direito à Educação é um direito fundamental indisponível. 
Artigo | Orçamento público para financiamento da assistência estudantil no enșino superior sob a perspectiva do direito humano fundamental à educação (MARTINS, Paulo Fernando de Melo; ARAÚJO JUNIOR, Carlos Alberto Moreira de; RODRIGUES, Jacqueline Araújo.

Outro aspecto importante é a gratuidade do ensino superior, também uma conquista social. A esse respeito, a Constituição Federal, de 1988, instituiu a obrigação do Estado pela viabilização do direito ao ensino de forma gratuita em estabelecimentos oficiais financiados com recursos públicos, o que inclui a educação superior, e assim disciplinou:

Art. 205. “A educação, direito de todos e dever do Estado e da família, será promovida e incentivada com a colaboração da sociedade, visando ao pleno desenvolvimento da pessoa, seu preparo para o exercício da cidadania e sua qualificação para o trabalho".

Art. 206. O ensino será ministrado com base nos seguintes princípios:

[...]

IV - gratuidade do ensino público em estabelecimentos oficiais (BRASIL, 1988).

A gratuidade do ensino em estabelecimentos oficiais já foi pacificada pelo Supremo Tribunal Federal, conforme dispõe a Súmula Vinculante no 12, publicada em 22 de agosto de 2008.

Diante desse pressuposto, fica mais claro perceber o compromisso de o Estado oferecer o ensino superior, por isso, também deve organizar a educação, a fim de permitir o ingresso das pessoas aos níveis mais elevados, consoante as disposições no art. 208 da Constituição Federal, de 1988: “Art. 208. O dever do Estado com a educação será efetivado mediante a garantia de: $\mathrm{V}$ - acesso aos níveis mais elevados do ensino, da pesquisa e da criação artística, segundo a capacidade de cada um" (BRASIL, 1988).

Ademais, cabe ao governo viabilizar adequadamente as condições para financiamento das instituições públicas federais, é o que se depreende do art. 211 da Constituição Federal:

Art. 211. A União, os Estados, o Distrito Federal e os Municípios organizarão em regime de colaboração seus sistemas de ensino.

10 A União organizará o sistema federal de ensino e o dos Territórios, financiará as instituições de ensino públicas federais e exercerá, em matéria educacional, função redistributiva e supletiva, de forma a garantir equalização de oportunidades educacionais e padrão mínimo de qualidade do ensino mediante assistência técnica e financeira aos Estados, ao Distrito Federal e aos Municípios (BRASIL, 1988). 
Artigo | Orçamento público para financiamento da assistência estudantil no enșino superior sob a perspectiva do direito humano fundamental à educação (MARTINS, Paulo Fernando de Melo; ARAÚJO JUNIOR, Carlos Alberto Moreira de; RODRIGUES, Jacqueline Araújo.

Nesse aspecto, sobre a organização e financiamento do ensino superior, entra a universidade pública, atualmente centro de disputas políticas e ideológicas. Cabe lembrar, nesse ponto, conforme ensina Chauí (2003), que a universidade pública, des de o seu surgimento, é considerada uma instituição social autônoma, atrelada à ideia de democracia e democratização do saber.

Essa instituição autônoma, universidade institucional, está em constante enfrentamento aos governos estabelecidos e registra crises desde a década de 1960. Cenário esse que reflete os momentos de crise do capital em que as disputas políticas e ideológicas impactam sobremaneira a destinação de recursos no âmbito do orçamento público.

O ideário defendido pelo governo atual não prioriza uma universidade focada na universalidade orientada para o espaço público e a diversidade, mas sim uma organização a ser guiada pela lógica gerencial de administração competitiva e particular do capitalismo que vislumbra o conhecimento como mercadoria, a universidade operacional.

Como é possível perceber, o direito à educação, tanto a básica como a superior, reconhecida como direito resguardado no artigo 60 da Constituição Federal, de 1988, deve ser considerado como direito humano fundamental e, por consequência, é dever estatal sua oferta e garantia, haja vista que, para o atendimento dos objetivos constitucionais, torna-se necessária a formação completa do cidadão.

\section{O Programa Nacional de Assistência Estudantil (Pnaes) como instrumento de efetivação do direito à educação}

Preliminarmente, é preciso lembrar que o crescimento do ensino superior no Brasil foi tardio se comparado à maioria de seus países vizinhos latino-americanos. Para os autores Castro, Seixas \& Cabral Neto (2010), o primeiro período de expansão do ensino superior no Brasil teve início a partir da década de 1940, a maioria das universidades era de caráter privado, as quais foram posteriormente estatizadas, dando surgimento à maior parte das universidades federais.

De acordo com esses autores, o segundo período se deu na década de 1970, em decorrência, por exemplo, da concentração urbana e da necessidade de melhorar a 
Artigo | Orçamento público para financiamento da assistência estudantil no enșino superior sob a perspectiva do direito humano fundamental à educação (MARTINS, Paulo Fernando de Melo; ARAÚJO JUNIOR, Carlos Alberto Moreira de; RODRIGUES, Jacqueline Araújo.

formação da mão de obra. O terceiro período, impulsionado pela globalização da economia mundial e com influência das ideias neoliberais, ocorreu por volta da década de 1990.

Tendo em vista a necessidade de inserção precoce no mercado de trabalho, com objetivo de realizar o próprio sustento, assim como a impossibilidade de a família auxiliar esse estudante, faz com que as insuficientes condições de alimentação, saúde, transporte, material didático e inclusão digital aumentem a evasão no ensino superior, prejudicando, dessa forma, o pleno direito à educação. Nesse contexto,

Seja pela dificuldade de se conciliar trabalho e escola seja pela perda de atrativo social da escola no que diz respeito às possibilidades reais de ascensão social via estudos ou ainda, em razão de que as al terações na esfera da produção acabaram por deslocar certos processos de qualificação da mão de obra, através de conhecimentos e informações, da escola para as próprias unidades produtivas ou por todos os fatores combinados, o fato é que a escola vinha se esvaziando qualitativa e quantitativamente de forma cada vez mais acelerada. Daí o conjunto de ações assistenciais que foi tomado para mudar esse quadro, inclusive na esfera da educação superior, onde são extremamente elevados os índices de evasão, chegando a cerca de 50\%. (ALMEIDA, 2000, p.73).

Daí a essencialidade da assistência estudantil, política com origem nas lutas da própria classe estudantil por melhores condições e permanência no ensino superior. Com o processo de expansão e democratização do acesso ao ensino superior no Brasil, principalmente em consequência das políticas de inclusão iniciadas no governo do expresidente Lula, houve o crescimento da quantidade de alunos de baixa renda com necessidade de suporte para permanência na universidade.

Os processos democratizantes mais amplos da educação superior brasileira ocorreram a partir de 2003, com os governos de Luiz Inácio Lula da Silva (2003-2010) e continuaram no primeiro governo de Dilma Rousseff (20112014), com a expansão da oferta de vagas, a construção de novas universidades públicas, a criação de cotas étnico-raciais e sociais e a implantação do PNAES. (SANTOS \& MARAFON, 2016, p. 411).

A assistência estudantil, com o Decreto no 7.234, de 19 de julho de 2010, ganhou status de política pública, ao instituir o Programa Nacional de Assistência Estudantil destinado a ampliar as condições de permanência dos jovens na educação 
Artigo | Orçamento público para financiamento da assistência estudantil no enșino superior sob a perspectiva do direito humano fundamental à educação (MARTINS, Paulo Fernando de Melo; ARAÚJO JUNIOR, Carlos Alberto Moreira de; RODRIGUES, Jacqueline Araújo.

superior pública federal. As principais áreas de ação são: atendimento à moradia, alimentação, transporte, saúde, inclusão digital, cultura, esporte, creche, apoio pedagógico e apoio a estudantes com deficiências, transtornos ou superdotação.

Dessarte, a partir das reflexões de Abreu (2012), a assistência estudantil foi concebida como estratégia para reduzir os efeitos das desigualdades sociais e, portanto, possibilitar o acesso e permanência dos estudantes no sistema educacional, contribuindo para sua inclusão no mundo do trabalho e na sociedade.

Diante desse panorama, a criação, em 2010, do Programa Nacional de Assistência Estudantilfoi um avanço na busca da igualdade de condições de permanência dos estudantes no ensino superior, tendo sido uma luta conjunta de segmentos ligados às universidades (dirigentes, docentes, servidores não docentes, discentes). O regulamento deste programa prioriza o atendimento dos estudantes oriundos da rede pública de ensino ou com renda familiar de até um salário mínimo e meio.

Diante de um cenário favorável ao setor privado, Sguissardi (2015) levanta uma importante discussão com a hipótese de massificação mercantilizadora da educação superior. Segundo este autor, até o final da década de 2014, a educação foi um dos mercados de ações mais lucrativos na Bovespa.

É que com a constante redução das fronteiras entre o espaço público e o privado, da expansão do ensino superior apoiada nas instituições privadas, de transformação do direito humano fundamental à educação em mercadoria, é possível pensar um cenário de massificação mercantil, em vez de democratização do acesso ao ensino superior.

Mostra-se relevante, pois, a argumentação de Sguissardi (2015), quando esse notável autor lembra a importância de lutar por políticas de democratização do acesso ao ensino superior, que, para não se tornar mera massificação, deve sustentar-se, ao menos na igualdade de condições de acesso, na escolha de cursos e carreiras a cursar, e de permanência com sucesso até o final dos estudos.

Outra problemática que merece destaque é o chamado processo de bolsificação da assistência estudantil; para as autoras Nascimento \& Arcoverde (2012, p. 172), este processo "exclui do debate a necessidade de universalização da política", daí a essencialidade de se pensar a assistência estudantil financiada pelo Estado numa 
Artigo | Orçamento público para financiamento da assistência estudantil no enșino superior sob a perspectiva do direito humano fundamental à educação (MARTINS, Paulo Fernando de Melo; ARAÚJO JUNIOR, Carlos Alberto Moreira de; RODRIGUES, Jacqueline Araújo.

concepção ampla e de qualidade aos alunos, em vez de ações focadas nas condições de sobrevivência.

De acordo com informações extraídas do Relatório da pesquisa sobre assistência estudantil na Universidade Federal do Tocantins (UFT, 2017), com a função de acompanhar os programas de assistência estudantil desenvolvidos nesta Universidade, os resultados demonstram o impacto positivo alcançado pelos auxílios concedidos no desenvolvimento e atendimento dos objetivos do Decreto no 7.234 , de 19 de julho de 2010.

Embora a assistência deva ser ampla e tenha de abranger diversas áreas, não há recursos orçamentários para o atendimento global, por isso, torna-se necessária a criação de formas para reconhecer quais as áreas devem ter prioridade de atendimento. Na Universidade Federal do Tocantins, a Pró-Reitoria de Assistência Estudantil (PROEST) realiza esse direcionamento por meio de pesquisas realizadas com os próprios alunos, de modo a verificar as necessidades com mais carência.

\section{Orçamento público para financiamento da assistência estudantil na Universidade Federal do Tocantins}

Impõe-se reconhecer, desde logo, que os debates em torno do papel do orçamento público como instrumento de Estado para efetivação dos direitos humanos evoluíram nas últimas décadas como emergente problemática diante dos discursos neoliberais diante dos problemas sociais.

Os recursos para o Programa Nacional de Assistência Estudantil são provenientes do Tesouro Nacional, mas há uma tendência de representatividade de recursos das próprias instituições federais de ensino superior, situação que pode revelar uma possível perda de autonomia universitária com a privatização interna e aplicação de seus próprios recursos para manutenção da assistência estudantil (MACHADO, 2017).

A Constituição Federal, de 1988, instituiu o Plano Plurianual (PPA) que norteará as políticas públicas, bem como as prioridades das ações de cada governo no período de quatro anos. Este Plano orienta a Lei de Diretrizes Orçamentárias (LDO) e a Lei Orçamentária Anual (LOA). Dessa forma, o planejamento governamental está vinculado aos orçamentos anuais aprovados por meio das Leis Orçamentárias Anuais (LOA). 
Artigo | Orçamento público para financiamento da assistência estudantil no enșino superior sob a perspectiva do direito humano fundamental à educação (MARTINS, Paulo Fernando de Melo; ARAÚJO JUNIOR, Carlos Alberto Moreira de; RODRIGUES, Jacqueline Araújo.

CF/88, Art. 165. Leis de iniciativa do Poder Executivo estabelecerão:

I - o plano plurianual;

II - as diretrizes orçamentárias;

III - os orçamentos anuais.

$\S$ 1o A lei que instituir o plano plurianual estabelecerá, de forma regionalizada, as diretrizes, objetivos e metas da administração pública federal para as despesas de capital e outras delas decorrentes e para as relativas aos programas de duração continuada.

Na Lei de Orçamento Anual, o governo define as receitas e as despesas públicas em vista de viabilizar o planejamento aprovado no Plano Plurianual. Nesse sentido, cabe destacar o posicionamento de Abreu \& Câmara (2014, p. 74) que considera o orçamento "como instrumento da ação governamental capaz de tornar factíveis, ou não, as ações governamentais, a depender do modo como é formalizado".

Por isso, a Lei do Orçamento Público não pode ser colocada à disposição de interesses políticos distantes dos anseios sociais, pois se trata de instrumento normativo de extrema importância para concretização das atividades estatais para materialização dos direitos fundamentais.

Cumpre ressaltar, nesse contexto, que, no Brasil, o orçamento é autorizativo; a esse respeito, conforme observam Oliveira \& Ferreira (2017), o orçamento tem caráter autorizativo e ainda continua sendo trabalhado como política de governo, em propostas, muitas vezes sem aplicação prática, e não como instrumento para concretização dos direitos sociais.

O governo trata suas prioridades de gestão no orçamento, então, este é um instrumento de controle de efetivação de políticas públicas, como é o caso da política de assistência estudantil que resultou na criação do Programa Nacional de Assistência Estudantil, em 2010, aprovado pelo Decreto no 7.234, de 19 de julho de 2010.

De acordo com o regulamento, o Programa deverá ser implementado com vista a atender aos estudantes de graduação presencial em instituições federais de ensino superior. A universidade pública, como agente importante de transformação social, possui enorme responsabilidade sobre a gestão dos recursos públicos destinados à universalização do acesso ao ensino superior diante das inúmeras situações de desigualdades sociais na sociedade brasileira, principalmente para os sujeitos historicamente excluídos da educação superior. 
Artigo | Orçamento público para financiamento da assistência estudantil no enșino superior sob a perspectiva do direito humano fundamental à educação (MARTINS, Paulo Fernando de Melo; ARAÚJO JUNIOR, Carlos Alberto Moreira de; RODRIGUES, Jacqueline Araújo.

O Programa Nacional de Assistência Estudantil, instituído pelo governo federal com o propósito de ampliar as condições de permanência dos estudantes no ensino superior público federal - aprovou as seguintes ações: (i) moradia estudantil; (ii) alimentação; (iii) transporte; (iv) atenção à saúde; (v) inclusão digital; (vi) cultura; (vii) esporte; (viii) creche; (ix) apoio pedagógico; e (x) acesso, participa ção e aprendizagem de estudantes com deficiência, transtornos globais do desenvolvimento e altas habilidades e superdotação.

Por sua notável relevância como importante instrumento para efetivação dos direitos sociais, adiante serão destacados os dados orçamentários destinados ao financiamento da política de assistência estudantil sob influência do Programa Nacional de Assistência Estudantil na Universidade Federal do Tocantins, com ênfase nos valores autorizados pelas Leis Orçamentárias (LOA), e nos Empenhados.

Pela apuração dos dados, têm-se as seguintes avaliações: a) comparação dos valores inicialmente previstos nas Leis Orçamentárias Anuais (LOA) com aqueles efetivamente empenhados do orçamento do Programa; b) verificação da evolução dos gastos; e c) identificação da execução orçamentária com as ações de assistência.

A criação do Programa Nacional de Assistência Estudantil proporcionou aumento progressivo de recursos para a assistência estudantil. Veja-se a evolução orçamentária federal, conforme gráfico 1 :

Gráfico 1: Programa Nacional de Assistência Estudantil (PNAES): Evolução do Orçamento (LOAs).

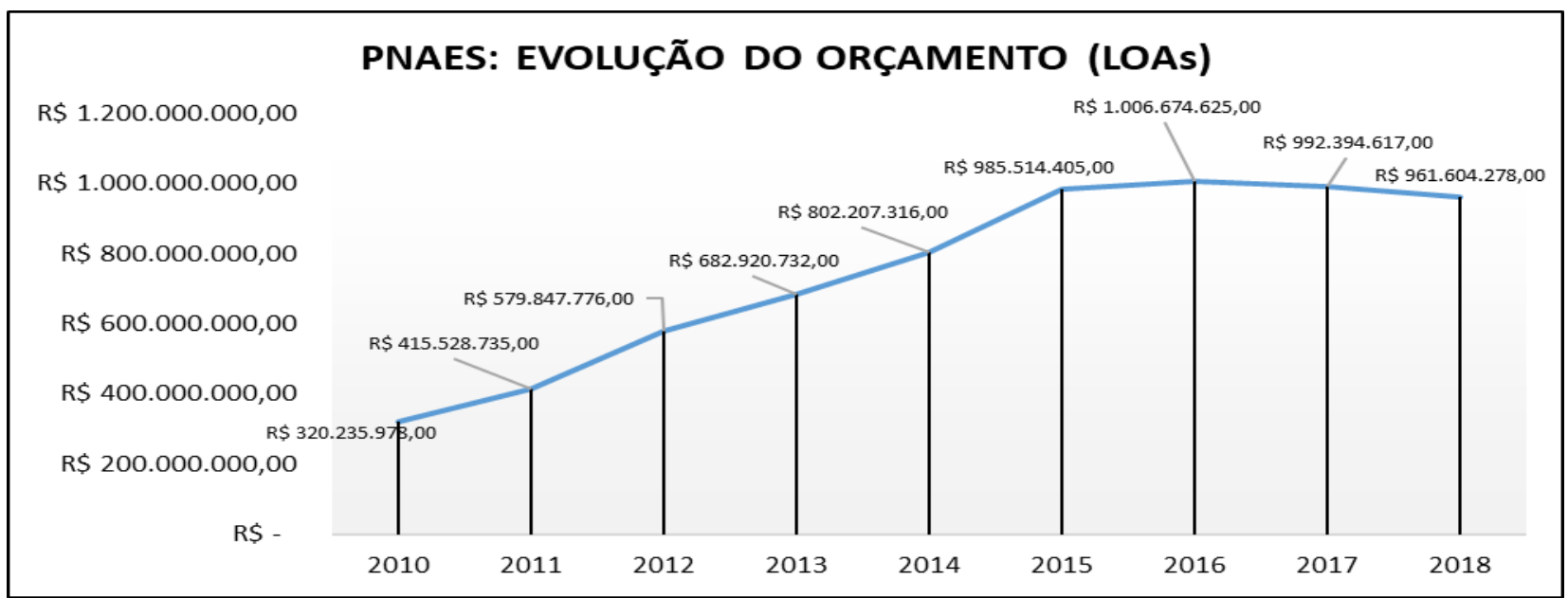

Fonte: Diretoria de Orçamento (UFT, 2018) / Elaboração própria.

Com base na trajetória do orçamento geral, no período de 2010 a 2016, as 
Artigo | Orçamento público para financiamento da assistência estudantil no enșino superior sob a perspectiva do direito humano fundamental à educação (MARTINS, Paulo Fernando de Melo; ARAÚJO JUNIOR, Carlos Alberto Moreira de; RODRIGUES, Jacqueline Araújo.

dotações foram crescentes, o maior orçamento (LOA) aprovado ocorreu em 2016 no valor atualizado $\mathrm{R} \$$ 1.006.674.625,00 (um billhão, seis milhões, seiscentos e setenta e quatro mil e seiscentos e vinte e cinco reais). A partir de 2016, a destinação de recurso orçamentário passou a sofrer retrações.

Quanto ao orçamento no âmbito da Universidade Federal do Tocantins, conforme se demonstra na tabela abaixo, realizou-se levantamento de informações de cunho econômico-financeiro de execução orçamentária numa perspectiva histórica de dotações das Leis Orçamentárias Anuais (LOA).

Tabela 1: Trajetória do Orçamento (LOA) PNAES/UFT, período de 2010 a 2018

\begin{tabular}{|c|c|c|c|c|}
\hline $\begin{array}{c}\text { Ano } \\
\text { Lançamento }\end{array}$ & $\begin{array}{l}\text { Dotação } \\
\text { Inicial }\end{array}$ & $\begin{array}{l}\text { Dotação } \\
\text { Atualizada }\end{array}$ & $\begin{array}{c}\text { Despesas } \\
\text { Empenhadas }\end{array}$ & $\begin{array}{c}\% \\
\text { executado }\end{array}$ \\
\hline 2010 & $\mathrm{R} \$ 5.143 .306,00$ & $\mathrm{R} \$ 5.143 .306,00$ & $\mathrm{R} \$ 5.143 .306,00$ & 100 \\
\hline 2011 & $\mathrm{R} \$ 5.411 .719,00$ & $\mathrm{R} \$ 5.411 .719,00$ & $R \$ 5.404 .024,22$ & 99,85 \\
\hline 2012 & $\mathrm{R} \$ 6.135 .593,00$ & $\mathrm{R} \$ 7.116 .460,00$ & $R \$ 6.016 .189,82$ & 84,54 \\
\hline 2013 & $\mathrm{R} \$ 6.968 .594,00$ & $\mathrm{R} \$ 6.968 .594,00$ & $R \$ 4.678 .697,27$ & 67,14 \\
\hline 2014 & $\mathrm{R} \$ 8.723 .191,00$ & $\mathrm{R} \$ \mathbf{8 . 7 2 3 . 1 9 1 , 0 0}$ & $\mathrm{R} \$ 6.984 .847,83$ & 80,10 \\
\hline 2015 & $\mathrm{R} \$ 16.626 .650,00$ & $\mathrm{R} \$ 13.626 .650,00$ & $\mathrm{R} \$ 9.654 .278,13$ & 70,85 \\
\hline 2016 & $\mathrm{R} \$ 18.268 .373,00$ & $\mathrm{R} \$ 18.268 .373,00$ & $\begin{array}{c}\mathrm{R} \$ \\
18.018 .940,76\end{array}$ & 98,64 \\
\hline 2017 & $\mathrm{R} \$ 17.738 .261,00$ & $\mathrm{R} \$ 17.738 .261,00$ & $\begin{array}{c}\mathrm{R} \$ \\
14.843 .296,54\end{array}$ & 83,68 \\
\hline 2018 & $\mathrm{R} \$ 17.367 .257,00$ & $\mathrm{R} \$ 17.367 .257,00$ & $\begin{array}{c}\mathrm{R} \$ \\
17.367 .257,00\end{array}$ & 100 \\
\hline
\end{tabular}

Fonte: Diretoria de Orçamento (UFT, 2018) / Elaboração própria.

Considerando a Tabela 1, é possível notar que na Universidade Federal do Tocantins as dotações (LOA) de recursos destinados ao Programa Nacional de Assistência Estudantil também foram crescentes no período de 2010 até 2016 . O maior aporte de recursos ocorreu em 2016, no valor de $\mathrm{R} \$$ 18.268.373,00 (dezoito milhões duzentos e sessenta e oito mil trezentos e setenta e três reais).

O maior volume de recursos empenhados também ocorreu no ano de 2016 em 
Artigo | Orçamento público para financiamento da assistência estudantil no enșino superior sob a perspectiva do direito humano fundamental à educação (MARTINS, Paulo Fernando de Melo; ARAÚJO JUNIOR, Carlos Alberto Moreira de; RODRIGUES, Jacqueline Araújo.

ralação aos demais períodos de execução orçamentária no valor de $\mathrm{R} \$ 1$ 18.018.940,76 (dezoito milhões dezoito mil novecentos e quarenta reais e setenta e seis centavos).

De outra banda, exceto nos anos 2010 e 2018, a execução do orçamento destinado ao Programa Nacional de Assistência estudantil, na Universidade Federal do Tocantins, ficou abaixo do crédito aprovado na Lei Orçamentária Anual, e o período de menor execução orçamentária, 67,14\%, ocorreu em 2013.

Ainda com relação à execução do orçamento, ou seja, recursos empenhados, em 2013 houve um recuo em relação ao exercício anterior, mas a situação voltou a ser crescente a partir de 2014. No exercício 2015 a destinação atualizada de recursos (LOA) teve um crescimento acentuado em relação aos períodos anteriores recebendo um incremento de $56,21 \%$ de recursos somando-se o valor de $\mathrm{R} \$ 13.626 .650,0$ (treze milhões seiscentos e vinte e seis mil seiscentos e cinquenta reais) em relação ao exercício anterior.

A tendência crescente na destinação de recursos (LOA) continuou até o total de $\mathrm{R} \$ 18.268 .373,00$ (dezoito milhões duzentos e sessenta e oito mil e trezentos e setenta três reais) recebidos no ano de 2016.

Com base na Tabela 1, fica evidente o registro de redução de recurso do orçamento (LOA) no total de $\mathrm{R} \$ 530.112,00$ (quinhentos e trinta mil, cento e doze reais) na LOA 2017 em relação ao exercício anterior. A dotação (LOA) referente ao exercício 2018 foi menor, num total de $\mathrm{R} \$ 371.004,00$ (trezentos e setenta e um mil e quatro reais) comparando-se com o ano 2017.

O cenário em 2017 mostra um recuo na execução de recursos se comparado com a situação em 2016. Quanto ao último exercício, 2018, o volume de recursos empenhados voltou à tendência crescente, mas ainda em menor volume em relação ao exercício 2016.

É possível afirmar que esses incrementos de recursos resultaram das políticas efetivas de ações do Programa Reuni (Reestruturação e Expansão das Universidades Federais) e da própria Assistência Estudantil aumentando os repasses de recursos da União para as Instituições de Ensino Superior Federal. 
Tabela 2: Execução do Orçamento PNAES/UFT - dotações empenhadas, no período de 2010-2018

\begin{tabular}{|c|c|c|c|c|c|c|c|c|c|c|c|c|}
\hline & & \multirow{2}{*}{\multicolumn{9}{|c|}{ EXECUÇÃO DO ORÇAMENTO PNAES - DOTAÇÕES EMPENHADAS NO PERIOODO DE 2010 A 2018}} & & \\
\hline & & & & & & & & & & & \multirow[b]{2}{*}{ TOTAL } & \multirow[b]{2}{*}{ TOTAL } \\
\hline \multirow{2}{*}{ Despesa } & \multirow{2}{*}{ Despesa Detalhada } & 2010 & 2011 & 2012 & 2013 & 2014 & 2015 & 2016 & 2017 & 2018 & & \\
\hline & & Movimento R\$ & Movimento R\$ & Movimento R\$ & Movimento R\$ & Movimento R\$ & Movimento R\$ & Movimento R\$ & Movimento R\$ & Movimento R\$ & Movimento R\$ & $\%$ \\
\hline$\overline{\text { AQUISIÇÃO }}$ & COMPRA DE SOFTWARE & & & & & & & $9.190,68$ & & & $9.190,68$ & 0,01 \\
\hline $\begin{array}{c}\text { OBRAS E } \\
\text { INSTALACOES }\end{array}$ & $\begin{array}{l}\text { RESTAURANTE } \\
\text { UNIVERSITARIO E } \\
\text { CANTINA }\end{array}$ & $2.359 .706,70$ & $3.497 .114,44$ & $1.890 .402,72$ & $71.819,27$ & $1.199 .606,63$ & $872.019,22$ & $370.008,24$ & & & $10.260 .677,22$ & 11,65 \\
\hline \multirow{7}{*}{$\begin{array}{l}\text { EQUIPAMENTOS } \\
\text { E MATERIAL } \\
\text { PERMANENTE }\end{array}$} & EQUIPAMENTOS DE TI & $640.293,30$ & & & & & & $1.301 .597,00$ & & $111.903,28$ & $2.053 .793,58$ & 2,33 \\
\hline & \begin{tabular}{|c|} 
APARELHOS E \\
USTENSÍLIOS DOMÉSTICOS
\end{tabular} & & & $575.405,00$ & $186.057,00$ & & & $80.663,68$ & & & $842.125,68$ & 0,96 \\
\hline & \begin{tabular}{|c|} 
EQUIPAMENTOS PARA \\
RESTAURANTE \\
UNIVERSITÁRIO \\
\end{tabular} & & & $116.060,00$ & $543.942,00$ & & & $134.581,20$ & & & $794.583,20$ & 0,90 \\
\hline & MOBILIÁRIOS EM GERAL & & & $400.801,00$ & $227.109,00$ & & & $1.077 .996,20$ & & $84.900,00$ & $1.790 .806,20$ & 2,03 \\
\hline & $\begin{array}{c}\text { APARELHOS DE MEDIÇĀO E } \\
\text { ESPORTIVOS DIVERSOS }\end{array}$ & & & & $3.750,00$ & & & & $15.140,13$ & & $18.890,13$ & 0,02 \\
\hline & $\begin{array}{l}\text { EQUIPAMENTOS DE ÁUDIO } \\
\text { E VÍDEO }\end{array}$ & & & & & & & $67.076,76$ & & & $67.076,76$ & 0,08 \\
\hline & \begin{tabular}{|l|} 
AQUISIÇÃO DE VEÍCULO \\
\end{tabular} & & & & & $318.000,00$ & & & & & $318.000,00$ & 0,36 \\
\hline \multirow{3}{*}{$\begin{array}{c}\text { AUXÍLIO } \\
\text { FINANCEIRO A } \\
\text { ESTUDANTES }\end{array}$} & BOLSAS DE ESTUDOS & $1.463 .303,00$ & $1.793 .720,16$ & $2.479 .683,24$ & $2.724 .980,00$ & $2.720 .712,00$ & $6.503 .580,00$ & $8.011 .573,14$ & $11.059 .784,00$ & $11.139 .088,33$ & $47.896 .423,87$ & 54,38 \\
\hline & $\begin{array}{l}\text { AUXÍLIO PARA ESTUDO E } \\
\text { PESOUISA }\end{array}$ & $330.000,00$ & & $480.657,89$ & $490.000,00$ & $550.000,00$ & & & & & $1.850 .657,89$ & 2,10 \\
\hline & $\begin{array}{c}\text { AUXÍLIO ATENÇÃO À } \\
\text { SAÚDE }\end{array}$ & & & & & & & $52.500,00$ & $77.000,00$ & $172.000,00$ & $301.500,00$ & 0,34 \\
\hline \multirow{5}{*}{$\begin{array}{l}\text { MATERIAL DE } \\
\text { CONSUMO }\end{array}$} & $\begin{array}{l}\text { MATERIAL EUCATIVO E } \\
\text { ESPORTIVO }\end{array}$ & & $7.998,84$ & & $2.240,00$ & $7.999,90$ & & & $57.657,86$ & & $75.896,60$ & 0,09 \\
\hline & GÁS E MATERTAIS & & & & & $90.280,00$ & & & & & $90.280,00$ & 0,10 \\
\hline & ALIMENTAÇÃOO & & & & & $811.890,75$ & $1.521 .018,04$ & & & & $2.332 .908,79$ & 2,65 \\
\hline & EQUTPAMENTOS DE TI & & & & & & & $4.011,00$ & $12.100,00$ & & $16.111,00$ & 0,02 \\
\hline & UTENSÍLIOS DOMÉSTICOS & & & & & & & & & $36.580,00$ & $36.580,00$ & 0,04 \\
\hline \multirow{2}{*}{$\begin{array}{l}\text { PASSAGENS E } \\
\text { DESPESAS COM } \\
\text { LOCOMOÇÃO }\end{array}$} & $\begin{array}{l}\text { LOCAÇÃO DE MEIOS DE } \\
\text { TRANSPORTE }\end{array}$ & $350.000,00$ & $105.190,79$ & & $400.000,00$ & $806.996,55$ & $564.164,12$ & $397.548,59$ & & & $2.623 .900,05$ & 2,98 \\
\hline & \begin{tabular}{|l|} 
PASSAGENS PARA O PAÍS \\
\end{tabular} & & & $4.056,10$ & & & & & & & $4.056,10$ & 0,00 \\
\hline \multirow{8}{*}{$\begin{array}{l}\text { OUTROS } \\
\text { SERVIÇOS DE } \\
\text { TERCEIROS }\end{array}$} & MANUTENÇÄO & & & & & & & & & $740.756,71$ & $740.756,71$ & 0,84 \\
\hline & ALIMENTAÇÃO & & & $2.900,00$ & & & & $6.469 .490,50$ & $2.883 .285,63$ & $4.898 .430,01$ & $14.254 .106,14$ & 16,18 \\
\hline & $\begin{array}{l}\text { SERVICOSOS GRÁFIFCOS; } \\
\text { AUDIO: VÍDEO }\end{array}$ & & & $27.611,87$ & & $171.900,00$ & & & & $153.023,62$ & $352.535,49$ & 0,40 \\
\hline & UNIFORMES E BANDEIRAS & & & $38.612,00$ & & & & & & & $38.612,00$ & 0,04 \\
\hline & EVENTOS/HOMENAGENS & & & & & $307.462,00$ & $179.806,60$ & & & & $487.268,60$ & 0,55 \\
\hline & LOCAÇÃOO DE IMÓVEL & & & & & & $13.690,15$ & $42.703,77$ & $38.328,92$ & $27.377,80$ & $122.100,64$ & 0,14 \\
\hline & ENERGIA ELÉTRTCA & & & & & & & & $700.000,00$ & & $700.000,00$ & 0,79 \\
\hline & & $5.143 .303,00$ & \begin{tabular}{|l|}
$5.404 .024,23$ \\
\end{tabular} & $6.016 .189,82$ & \begin{tabular}{|l|}
$4.649 .897,27$ \\
\end{tabular} & $6.984 .847,83$ & $9.654 .278,13$ & $18.018 .940,76$ & $14.843 .296,54$ & \begin{tabular}{|l|l|}
$17.364 .059,75$ \\
\end{tabular} & \begin{tabular}{|l|l|}
$88.078 .837,33$ \\
\end{tabular} & 100,00 \\
\hline
\end{tabular}

Fonte: Diretoria de Orçamento (UFT, 2018) / Elaboração própria 
Artigo | Orçamento público para financiamento da assistência estudantil no enșino superior sob a perspectiva do direito humano fundamental à educação (MARTINS, Paulo Fernando de Melo; ARAÚJO JUNIOR, Carlos Alberto Moreira de; RODRIGUES, Jacqueline Araújo.

Segundo mostra a Tabela 2, quanto à gestão do recurso pela Universidade Federal do Tocantins, a destinação de recursos para bolsas e auxílios financeiros se manteve numa tendência crescente de dotações em todo o período de 2010 a 2018. É importante notar que a utilização das dotações com bolsas e auxílios financeiros representa mais de 50\% do recurso do Programa Nacional de Assistência Estudantil. A alimentação ocupa a segunda posição nos dispêndios financeiros com mais de $16 \%$ na participação do total dos gastos.

Diante desse cenário, de luta contra violaçãoe/ou redução dos direitos humanos fundamentais, como a educação, é expressivo o ponto de vista de Blyberg (2009), no qual as pesquisas voltadas para temas sobre orçamento público na perspectiva de promoção dos direitos humanos têm crescido e podem ajudar, tendo em vista a dificuldade de compreensão das informações financeiras disponíveis sobre os gastos públicos, a denunciar violações de direitos.

\section{Considerações finais}

O orçamento público, com suas regras dispostas na Constituição Federal, passou por importante evolução e se inseriu como peça indispensável à atividade de planejamento governamental; desta feita, o seu manuseio na gestão pública deveria se isentar das disputas de poder e se concentrar na concretização dos direitos humanos fundamentais.

Urge ressaltar, portanto, que a assistência estudantil é uma política relevante e a cada dia tem despertado mais interesse em consequência das políticas de inclusão iniciadas em tempos recentes em razão do crescimento do quantitativo de alunos de baixa renda nas IFES com necessidade dos recursos públicos para continuidade dos estudos na universidade.

De outro modo, o impeachment de 2016 amplia o espaço de influência a setores políticos e econômicos no ambiente do governo federal os quais têm obtido importantes vitórias na adoção de uma agenda neoliberal no Brasil, atribuindo às políticas sociais a responsabilidade pelo desequilíbrio nas contas do Governo.

Numa perspectiva de direito fundamental, a situação é preocupante, em vista, 
Artigo | Orçamento público para financiamento da assistência estudantil no enșino superior sob a perspectiva do direito humano fundamental à educação (MARTINS, Paulo Fernando de Melo; ARAÚJO JUNIOR, Carlos Alberto Moreira de; RODRIGUES, Jacqueline Araújo.

primeiro, da atitude assumida pela corrente política do ex-presidente Michel Temer que se instalou no país após o impeachment de 2016; em segundo lugar, pelo indicativo do bloqueio de recursos no governo do presidente Jair Bolsonaro, destinados às universidades federais, situação esta que aponta para um cenário possível de retrocesso social, uma vez que é expressiva a participação do Programa Nacional de Assistência Estudantil na efetivação do direito fundamental à educação, em especial, ao ensino superior.

Reduzir o orçamento de política social, como a do ensino superior público, não é solução para o equilíbrio de contas públicas, e sim um verdadeiro retrocesso social. As dotações de recursos para as Universidades Públicas Federais com o Programa Nacional de Assistência Estudantil buscam ampliar as condições de permanência dos jovens na educação superior para promoção do direito humano fundamental à educação.

Vale destacar, com isso, o posicionamento de Hunt (2009), no qual os direitos humanos demandam ativa participação de seus detentores. Assim, diante dos inúmeros problemas que marcaram a história da democracia brasileira, as pesquisas sobre a destinação e execução do orçamento público são indispensáveis à participação e controle social em prol de universidade pública democrática e popular para melhor efetivação dos direitos humanos fundamentais.

Dessarte, em razão da retração na movimentação de recursos, e considerandose as marcas das lutas sociais travadas para a composição de conquistas no orçamento público, confirma-se a importância do monitoramento do volume de recursos destinados à promoção dos direitos humanos.

\section{Bibliografia}

ABREU, Edna Maria Coimbra de. A assistência estudantil no contexto da expansão da educação profissional e tecnológica. 2012. 197 f. Dissertação (Mestrado em Políticas Públicas) - Universidade Federal do Maranhão, São Luís, 2012.

UNIVERSIDADE FEDERAL DO TOCANTINS. Relatório da Pesquisa sobre Assistência estudantil na UFT. PROEST, UFT, 2017. Disponível em: <http://download.uft.edu.br/?d=a491c2ab-5745-4ef1-bc5661ec9c852e32;1.0:Relat\%C3\%B3rio\%20Pesquisa\%20Assist\%C3\%AAncia\%20Estudantil \%20-\%202017.pdf>. Acesso em 04 dez. 2018. 
Artigo | Orçamento público para financiamento da assistência estudantil no enșino superior sob a perspectiva do direito humano fundamental à educação (MARTINS, Paulo Fernando de Melo; ARAÚJO JUNIOR, Carlos Alberto Moreira de; RODRIGUES, Jacqueline Araújo.

ABREU, Rodrigues de; CÂMARA, Leonor Moreira. O orçamento público como instrumento de ação governamental: uma análise de suas redefinições no contexto da formulação de políticas públicas de infraestrutura. Rev. Adm. Pública, Rio de Janeiro, v. 17, n. 49(1), p. 73-90, 2015. Disponível em: <http://www.scielo.br/pdf/rap/v49n1/00347612-rap-49-01-00073.pdf> Acesso em: 26 jul. 2018.

ALMEIDA, Ney L. T. Educação Pública e Serviço Social. Revista Serviço Social e Sociedade no 63. São Paulo: Cortez, 2000. Disponível em: < http://www.uel.br/revistas/ssrevista/c_v5n1_Jo.htm>. Acesso em 03 de abr. 2019.

ALVES, Jolinda Moraes. A assistência estudantil no âmbito da política de educação superior pública. Serviço Social em Revista, Londrina, Paraná, v.5, n 1, jul./dez. 2002. Disponível em: <http://www.ssrevista.uel.revista/c_v5n1_Jo.htm>. Acesso em: 10 jul. 2018.

ANDRADE, Júlio Thalles de Oliveira. Os direitos fundamentais sociais à luz do princípio da vedação ao retrocesso social. Revista Eletrônica Direito e Política, Programa de Pós-Graduação Stricto Sensu em Ciência Jurídica da UNIVALI, Itajaí, v.11, n.1, 10 quadrimestre de 2016. Disponível em:<www.univali.br/direitoepolitica> Acesso em: 24 jul. 2018.

BARROSO, Luís Roberto. O Direito Constitucional e a Efetividade de suas Normas. 5. ed. Rio de Janeiro: Renovar, 2001.

BLYBERG, Ann. O Caso da Alocação Indevida: direitos econômicos e sociais e o orçamento público. Revista Internacional de Direitos Humanos. V. 6, n. 11, p. 135-153, dez. $2009 . \quad$ Disponível em:< http://www.scielo.br/scielo.php?script=sci_arttext\&pid=S1806-64452009000200007> Acesso em: 25 jul. 2018.

BOBBIO, Norberto. A Era dos Direitos. Rio de Janeiro: Elsevier, 2004.

BRASIL. Constituição Federal de 1988. Disponível em:< http://www.planalto.gov.br/ccivil_03/constituicao/constituicao.htm>. Acesso em: 23 jul. 2018.

. Decreto no 591, de 6 de julho de 1992. Atos Internacionais. Pacto Internacional sobre Direitos Econômicos, Sociais e Culturais. Disponível em:< http://www.planalto.gov.br/ccivil_03/decreto/1990-1994/d0591.htm> Acesso em: 23 jul. 2018.

Decreto $\mathrm{n}^{\circ}$ 7.234, de 19 de julho de 2010. Programa de Nacional de Assistência Estudantil - Pnaes. Disponível em: www.mec.gov.br. Acesso em: 10 jul. 2018. . Lei $\mathrm{n}$ - 9.394, de 20 de dezembro de 1996. Estabelece as diretrizes $e$ bases da educação nacional. Disponível em: < http://www.planalto.gov.br/ccivil_03/leis/19394.htm>. Acesso em 25 abr. 2019. Supremo Tribunal Federal. STF, AR 594.018, Relator: Min. Eros Grau, DJ. 07/08/2009.

Supremo Tribunal Federal. STF, T.2. ARE 639.337 AgR/SP. Rel. Celso de Mello. DJ. 23/8/2011). 
Artigo | Orçamento público para financiamento da assistência estudantil no enșino superior sob a perspectiva do direito humano fundamental à educação (MARTINS, Paulo Fernando de Melo; ARAÚJO JUNIOR, Carlos Alberto Moreira de; RODRIGUES, Jacqueline Araújo.

. Supremo Tribunal Federal. STF, Súmula Vinculante $n$ o 12. A de taxa de matrícula nas universidades públicas viola o disposto no art. 206, IV, da Constituição Federal. Data de Aprovação. Sessão Plenária de 13/08/2008. Fonte de Publicação. DJe no 157 de 22/08/2008, p. 1. DOU de 22/08/2008, p. 1.

CANDAU, Vera Maria Ferrão. Direito à educação, diversidade e educação em direitos humanos. Educação e Sociedade. V. 33, n. 120, p. 715-726, jul/set. 2012.

CASTILHO, Ricardo. Direitos Humanos. 4. ed. São Paulo: Saraiva, 2017.

CASTRO, Alda Maria Duarte Araújo; SEIXAS, Ana Maria; Cabral Neto, Antônio. Políticas educativas em contextos globalizados: a expansão do ensino superior em Portugal e no Brasil. Revista Portuguesa de Pedagogia. v. 1, no 44, p. 37-61. 2010. Disponível em: http://flacso.org.br/files/2016/11/1270-3430-1-PB.pdf> Acesso em: 26 de maio de 2019.

CHAUÍ, Marilena de S. A Universidade pública sob nova perspectiva. Revista Brasileira de Educação. São Paulo. no 24. p. 5-15. 2003.

DECLARAÇÃO UNIVERSAL DOS DIREITOS HUMANOS. Assembleia Geral das Nações

Unidas em Paris. 10 dez. 1948. Disponível em: < https://www.ohchr.org/EN/UDHR/Documents/UDHR_Translations/por.pdf>. Acesso em: 26 abr. 2019.

DIAS, Adelaide Alves. Da educação como direito humano aos direitos humanos como princípio educativo. In: Educação em Direitos Humanos: Fundamentos teóricometodológicos/ Rosa Maria Godoy Silveira, et al. - João Pessoa: Editora Universitária, 2007. 513p.

HUNT, Lynn. A Invenção dos Direitos Humanos: uma história. São Paulo: Companhia das Letras, 2009.

LÁZARO, André. Educação e desigualdade: o papel do PROUNI. Revista ProUni MEC/SESu. Edição 01/2008. Disponível em <http://portal.mec.gov.br/prouni/arquivos/pdf/Revista_ProUni/Revista_ProUni.pdf> Acesso em: 24 jul. 2018.

MACHADO, Fernanda Meneghini. Financiamento da Assistência Estudantil nas Universidades Federais. Temporalis, Brasília - DF, V. 17, n. 33, p. 231-252, 2017. Disponível em: http://periodicos.ufes.br/temporalis/article/view/15560. Acesso em: 22 jul. 2017.

MARTINS, Paulo Fernando de M.; GUIMARÃES, Halyny Mendes. A formação de professores em direitos humanos: o debate necessário na construção de uma proposta pedagógica democrática. In: ROLIM, C.L.A.; et al (Orgs.). Educação como espaço de direito: formação, docência e discência. Jundiaí: Editora Paco Editorial, 2017.

MENEGON, Tiago Guilherme e outros. O Ensino Superior no Brasil: Breve Trajetória Histórica. Revista de Ciências Sociais do Norte do Mato Grosso - Nativa. № 1, volume $7-2018$. 
Artigo | Orçamento público para financiamento da assistência estudantil no enșino superior sob a perspectiva do direito humano fundamental à educação (MARTINS, Paulo Fernando de Melo; ARAÚJO JUNIOR, Carlos Alberto Moreira de; RODRIGUES, Jacqueline Araújo.

MOURA, Emerson Affonso da Costa; RIBEIRO, Jamir Calili. Direitos Fundamentais Sociais, Orçamentos Públicos e Reserva do Possível: $O$ dever de Progressividade nos Gastos Públicos. Revista de Direito Brasileira, São Paulo, v. 16, no 7, p. 225-241, 2017.

NASCIMENTO, Clara Martins do; ARCOVERDE, Ana Cristina Brito. O serviço social na assistência estudantil: reflexões acerca da dimensão político-pedagógica da profissão. In: FÓRUM NACIONAL DE PRÓ-REITORES DE ASSUNTOS COMUNITÁRIOS E ESTUDANTIS - Fonaprace. Revista Comemorativa 25 anos: histórias, memórias e múltiplos olhares. Uberlância: UFU-PROEX, 2012. p. 167-79.

NOVELINO, Marcelo; CUNHA JUNIOR, Dirley da. Constituição Federal para Concursos: doutrina, jurisprudência e questões comentadas. 9. ed. Revista Atualizada e Ampliada. Bahia: Editora Jus podium, 2018.

OLIVEIRA, Cláudio Ladeira de; FERREIRA, Francisco Gilney Bezerra de Carvalho. $O$ Orçamento Público no Estado Constitucional Democrático e a Deficiência Crônica das Finanças Públicas no brasil. Revista Sequência, n. 76, p. 183-212, ago. 2017. Disponível em: http://www.scielo.br/pdf/seq/n76/2177-7055-seq-76-00183.pdf. Acesso em 08 dez. 2018.

PIOVESAN, Flávia. Direitos humanos e o direito constitucional internacional. 13. ed. São Paulo: Saraiva, 2012.

. Sistema Internacional de Proteção dos Direitos Humanos. I Colóquio Internacional de Direitos Humanos. São Paulo, Brasil, 2001. Disponível em:< http://www.dhnet.org.br/direitos/sip/textos/a_pdf/piovesan_sip.pdf>. Acesso em: 23 dez. 2018.

SANTOS, Claudia Priscila Chupel; MARAFON, Nelize Moscon. A política de assistência estudantil na universidade pública brasileira: desafios para o serviço social. Textos \& Contextos (Porto Alegre), v. 15, n. 2, p. 408 - 422, ago./dez. 2016.

SGUISSARDI, Valdemar. Educação Superior no Brasil: democratização ou massificação mercantil? Revista Edcuc. Soc. Campinas, v. 36, № 133, p. 867-889, ago./dez. 2015.

SILVA, José Afonso da. Curso de Direito Constitucional Positivo. 26. ed. rev. e atual. São Paulo: Malheiros, 2006.

TAVEIRA, Christiano de Oliveira; MARÇAL, Thaís Boia. Proibição do retrocesso social e orçamento: em busca de uma relação harmônica. Revista de Direito Administrativo. v. 264, p. 161-186, set/dez 2013.

TEIXEIRA, Anísio. Educação não é privilégio. Rio de Janeiro: José Olympio Editor, 1957. 